\title{
PLASMA DISPOSITION OF CEFOPERAZONE AFTER SINGLE INTRAVENOUS AND INTRAMUSCULAR ADMINISTRATIONS IN CAMELS (CAMELUS DROMEDARIUS)
}

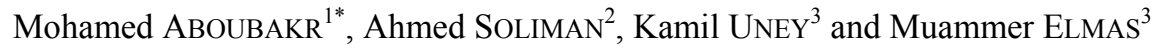 \\ ${ }^{1}$ Pharmacology Department, Faculty of Veterinary Medicine, Benha University, \\ 13736 Moshtohor, Toukh, Qalioubeya, Egypt; ${ }^{2}$ Pharmacology Department, Faculty of \\ Veterinary Medicine, Cairo University, Giza, Egypt; ${ }^{3}$ Department of Pharmacology and \\ Toxicology, Faculty of Veterinary Medicine, University of Selcuk, Konya, Turkey
}

(Received 18 March 2018; accepted 25 July 2018)

The plasma disposition of cefoperazone was investigated after intravenous (IV) and intramuscular (IM) administrations of $20 \mathrm{mg} / \mathrm{kg}$ as a single dose in six camels (Camelus dromedarius) in a crossover design. Blood plasma samples were analysed by high-performance liquid chromatography (HPLC). After IV administration, elimination half-life $\left(\mathrm{t}_{1 / 2 \beta}\right)$, volume of distribution at steady state $\left(\mathrm{V}_{\mathrm{dss}}\right)$, total body clearance $\left(\mathrm{Cl}_{\text {tot }}\right)$ and mean residence time (MRT) of cefoperazone were $1.95 \mathrm{~h}, 0.38 \mathrm{~L} / \mathrm{kg}, 0.17 \mathrm{~L} / \mathrm{h} / \mathrm{kg}$ and $2.16 \mathrm{~h}$, respectively. After IM administration of cefoperazone, peak plasma concentration $\left(\mathrm{C}_{\max }\right)$ was $21.95 \mu \mathrm{g} / \mathrm{mL}$ and it was obtained at $\left(\mathrm{t}_{\max }\right) 1.23 \mathrm{~h}$. Absorption half-life $\left(\mathrm{t}_{1 / 2 \mathrm{ab}}\right)$, elimination half-life and mean absorption time were $0.45 \mathrm{~h}, 2.84 \mathrm{~h}$ and $2.07 \mathrm{~h}$, respectively. The bioavailability of cefoperazone was $89.42 \%$. The lack of local reaction or any other adverse effects and the very good bioavailability following IM administration indicate that cefoperazone might be a promising alternative treatment for a variety of infectious diseases in camels.

Key words: Cefoperazone, concentrations, bioavailability, camels

Cefoperazone is a safe third-generation cephalosporin with few adverse effects, having broad-spectrum activity against Gram-positive, Gram-negative and anaerobic bacteria. Cefoperazone is very active against most strains of the family Enterobacteriaceae and Pseudomonas aeruginosa (Gupta et al., 2008).

Pharmacokinetic studies of cefoperazone had been conducted in different animals such as sheep (Guerrini et al., 1985), calves (Carli et al., 1986), rabbits (Marino et al., 1987), unweaned calves (Soback and Ziv, 1989), horses (Soraci et al., 1996), dogs (Montesissa et al., 2003), buffalo calves (Goyal et al., 2005), cross-bred calves (Gupta et al., 2008), and goats (Attia et al., 2015).

\footnotetext{
*Corresponding author; E-mail: mohamed.aboubakr@fvtm.bu.edu.eg;

Phone: 0020-1099874671; Fax: 0020-132463074
} 
No data on the pharmacokinetics of cefoperazone had been reported in camels. This study investigated the plasma disposition profile of cefoperazone after a single IV and IM administration of $20 \mathrm{mg} / \mathrm{kg}$ body weight in camels.

\section{Materials and methods}

\section{Animals}

Six clinically healthy male camels (body weight: 400-500 kg, age: 6-7 years) were used. Camels had not received any drug for at least two months before the study and were fed concentrates and hay, with water provided freely. The Ethics Committee of the Faculty of Veterinary Medicine, Cairo University, approved the use of camels and study protocols.

\section{Experimental design}

A crossover design $(3 \times 3)$ was used in this study; cefoperazone $(20 \mathrm{mg} / \mathrm{kg})$ was administered IV ( 3 camels; right jugular vein) or IM ( 3 camels; left neck muscles) to each camel as assigned. After a 2-week 'washout' period, camels that had been dosed IM with cefoperazone were injected IV, and vice versa. Cefoperazone was obtained as a sterile injectable powder $\left(\right.$ Cefobid $^{\circledR}$, cefoperazone sodium powder produced by SmithKline Beecham for Pfizer, Egypt) and dissolved in sterile saline immediately prior to administration.

A $10-\mathrm{mL}$ blood sample was collected from each camel by jugular venipuncture into tubes containing heparin from the left jugular vein at $0 \mathrm{~min}$ and at $0.08,0.16,0.25,0.5,1,2,4,6,8,12$ and $24 \mathrm{~h}$ after administration. Blood samples were centrifuged at $3000 \mathrm{~g}$ for $15 \mathrm{~min}$ and the plasma was stored at $-20{ }^{\circ} \mathrm{C}$ until analysis by high-performance liquid chromatography (HPLC).

\section{Analytical method}

Plasma cefoperazone concentrations were determined by HPLC according to Haghgoo et al. (1995). An HPLC system (Shimadzu Corporation, Kyoto, Japan) with a reverse-phase $\mathrm{C}_{18}$ analytical column (Whatman ${ }^{\circledR}$, MA, USA, $4.60 \times 100 \mathrm{~mm}$ internal diameter, particle size $5 \mu \mathrm{m}$ ) at room temperature was used for separation and reading at $266 \mathrm{~nm}$ wavelength using an UV detector (Shimadzu, SPD10A UV detector, Shimadzu Corporation). The mobile phase was $30 \mathrm{mM} \mathrm{KH}_{2} \mathrm{PO}_{4}$ buffer and methanol $(70: 30, \mathrm{v} / \mathrm{v})$ at a $\mathrm{pH}$ of 5.0. The mobile phase was filtered through $0.45 \mu \mathrm{m}$ filters and was pumped into the column at a flow rate of $1.0 \mathrm{~mL} /$ min at ambient temperature. Plasma samples $(50 \mu \mathrm{l})$ were deproteinised by adding a solution containing $50 \mu \mathrm{l}$ of $10 \%$ perchloric acid and $50 \mu \mathrm{l}$ of a mixture of acetonitrile $(50 \%)$ and methanol $(50 \%)$, and were mixed in a clean centrifuge tube by shaking on a vortex mixer for $1 \mathrm{~min}$; after centrifugation at 10,000 $\mathrm{g}$ at 
$5{ }^{\circ} \mathrm{C}$ for $5 \mathrm{~min}$, the clear supernatant was transferred to an autosampler vial and a $20 \mu \mathrm{l}$ aliquot was injected into the HPLC system.

The calibration curves were performed between 0.5 and $200 \mu \mathrm{g} / \mathrm{mL}$ using blank camel plasma. The standard curve of cefoperazone was linear with a correlation coefficient of 0.99 . The retention time of cefoperazone in camel plasma was approximately $9.7 \mathrm{~min}$. LOD was $0.1 \mu \mathrm{g} / \mathrm{mL}$, LOQ was $0.5 \mu \mathrm{g} / \mathrm{mL}$, and CV was $<15 \%$. The mean percentage recovery values for cefoperazone in plasma samples spiked at concentrations of 1,10 and $20 \mu \mathrm{g} / \mathrm{mL}$ were $98.37 \pm 4.28 \%$, $97.19 \pm 3.53 \%$ and $94.06 \pm 3.41 \%$, respectively. Intra-assay CV values ranged from 2.62 to $3.08 \%(\mathrm{n}=5,3$ times). The inter-assay $\mathrm{CV}$ varied from 3.49 to $4.73 \%(\mathrm{n}=5,3$ times, 3 days $)$.

\section{Pharmacokinetic analysis}

Plasma cefoperazone concentrations after IV and IM administrations were subjected to analysis using a computerised WinNonlin 6.3 program (Pharsight, Mountain View CA, USA). For IV and IM data, the appropriate pharmacokinetic model was determined by visual examination of individual plasma concentration versus time curves and by application of the Akaike information criterion (Yamaoka et al., 1978) resulting in the following two-compartmental model being chosen for data analysis. Half-lives were calculated using of the following equations:

$$
\begin{aligned}
& \mathrm{t}_{1 / 2 \mathrm{ab}}=\ln (2) / \mathrm{k}_{\mathrm{ab}} \\
& \mathrm{t}_{1 / 2 \alpha}=\ln (2) / \alpha \\
& \mathrm{t}_{1 / 2 \beta}=\ln (2) / \beta,
\end{aligned}
$$

where $\mathrm{k}_{\mathrm{ab}}, \alpha$, and $\beta$ are the absorption, distribution and elimination rate constants, respectively. AUC and AUMC were calculated using the method of trapezoids with extrapolation to infinity (Gibaldi and Perrier, 1982).

Absolute bioavailability $(\mathrm{F})=\mathrm{AUC}_{\mathrm{IM}} / \mathrm{AUC}_{\mathrm{IV}} \times 100$; mean absorption time $(\mathrm{MAT})=\mathrm{MRT}_{\mathrm{IM}}-\mathrm{MRT}_{\mathrm{IV}}$. For IV data, $\mathrm{Vd}_{\mathrm{ss}}$ was estimated as follows: $\mathrm{Vd}_{\mathrm{ss}}=$ dose $\times$ AUMC/AUC ${ }^{2}$ and $C L=$ dose $/ A U C$.

\section{Statistical analysis}

The results obtained were displayed as mean \pm SE. The paired $t$ test was used to test for differences between the two administration routes. The statistical software SPSS version 16 (SPSS Inc., Chicago, USA) was used for statistical analysis and values of $\mathrm{P}<0.05$ were considered significant. 


\section{Results}

No side effects occurred after either of the two administrations routes in camels. Plasma concentration-time profiles of cefoperazone $(20 \mathrm{mg} / \mathrm{kg}$ body weight) after single IV and IM administrations are presented in Fig. 1. The values of pharmacokinetic parameters estimated from the curve fitting are shown in Table 1. Following IV administration, $\mathrm{t}_{1 / 2 \alpha}$ and $\mathrm{t}_{1 / 2 \beta}$ were 0.18 and $1.95 \mathrm{~h}$, respectively. Following IM administration the corresponding pharmacokinetic variables were $\mathrm{t}_{1 / 2 \mathrm{ab}} 0.45 \mathrm{~h}, \mathrm{C}_{\max } 21.95 \mu \mathrm{g} / \mathrm{mL}$ at $\mathrm{t}_{\max } 1.23 \mathrm{~h}$ and $\mathrm{t}_{1 / 2 \beta} 2.84 \mathrm{~h}$, while bioavailability was $89.42 \%$.

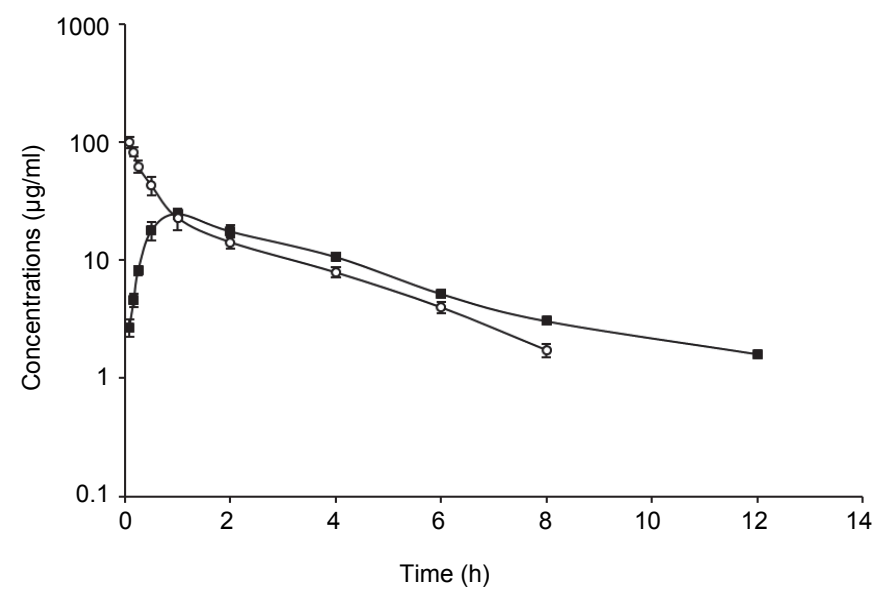

Fig. 1. Semi-logarithmic graph depicting the time-concentration of cefoperazone in the plasma of camels after a single IV (०) and IM ( $\bullet$ ) administration of $20 \mathrm{mg} / \mathrm{kg}$ body weight $(\mathrm{n}=6)$

\section{Discussion}

Following IV administration, the disposition of cefoperazone followed a two-compartment open model, which is consistent with previous reports on cefoperazone in horses (Soraci et al., 1996) and dogs (Montesissa et al., 2003), and it was similar to the disposition of other cephalosporins in camels such as ceftiofur (Goudah, 2007), ceftriaxone (Goudah, 2008), cefepime (Goudah et al., 2009), and ceftazidime (Goudah and Hasabelnaby, 2013).

Cefoperazone has a short distribution half-life $\left(\mathrm{t}_{1 / 2 \alpha}=0.18 \mathrm{~h}\right)$. Similar findings have been recorded in calves $(0.15 \mathrm{~h}$; Carli et al., 1986), dogs (Montesissa et al., 2003), longer than cefoperazone in horses (0.07 h; Soraci et al., 1996) and shorter than other cephalosporins in camels such as ceftiofur $(0.3 \mathrm{~h}$; Goudah, 2007), ceftriaxone $(0.27 \mathrm{~h}$; Goudah, 2008), cefepime $(0.3 \mathrm{~h}$; Goudah et al., 2009), and ceftazidime (0.3 h; Goudah and Hasabelnaby, 2013). 
Table 1

Plasma pharmacokinetic parameters (mean $\pm \mathrm{SE}$ ) of cefoperazone in camels following IV and IM administration of $20 \mathrm{mg} / \mathrm{kg}$ body weight $(\mathrm{n}=6)$

\begin{tabular}{lccc}
\hline Parameters & Unit & IV & IM \\
\hline $\mathrm{t}_{1 / 2 \mathrm{ab}}$ & $\mathrm{h}$ & - & $0.45 \pm 0.05$ \\
$\mathrm{t}_{1 / 2 \alpha}$ & $\mathrm{h}$ & $0.18 \pm 0.02$ & $0.54 \pm 0.04^{* *}$ \\
$\mathrm{t}_{1 / 2 \beta}$ & $\mathrm{h}$ & $1.95 \pm 0.05$ & $2.84 \pm 0.13^{* * *}$ \\
$\mathrm{AUC}$ & $\mu \mathrm{g} \mathrm{mL}^{-1} \mathrm{~h}^{-1}$ & $116.13 \pm 6.31$ & $103.65 \pm 5.23^{* * *}$ \\
$\mathrm{AUMC}$ & $\mu \mathrm{gL}^{-1} \mathrm{~h}^{-2}$ & $251.24 \pm 12.01$ & $444.49 \pm 28.63^{* * *}$ \\
$\mathrm{MRT}$ & $\mathrm{h}$ & $2.16 \pm 0.03$ & $4.26 \pm 0.08^{* * *}$ \\
$\mathrm{MAT}$ & $\mathrm{h}$ & - & $2.07 \pm 0.09$ \\
$\mathrm{Vd}_{\text {ss }}$ & $\mathrm{L} \mathrm{kg}^{-1}$ & $0.38 \pm 0.02$ & - \\
$\mathrm{Cl}_{\text {tot }}$ & $\mathrm{L} \mathrm{kg}^{-1} \mathrm{~h}^{-1}$ & $0.174 \pm 0.009$ & - \\
$\mathrm{C}_{\max }$ & $\mu \mathrm{g} \mathrm{mL}^{-1}$ & - & $21.95 \pm 0.68$ \\
$\mathrm{t}_{\max }$ & $\mathrm{h}_{\mathrm{F}}$ & - & $1.23 \pm 0.04$ \\
& $\%$ & - & $89.42 \pm 1.74$
\end{tabular}

${ }^{* *} \mathrm{P}<0.01 ;{ }^{* * *} \mathrm{P}<0.001 ;-$ : not calculated; $\mathrm{t}_{1 / 2 \mathrm{ab}}$ : absorption half-life after IM administration; $\mathrm{t}_{1 / 2 \alpha}$ : distribution half-life; $\mathrm{t}_{1 / 2 \beta}$ : elimination half-life; AUC: area under plasma concentrationtime curve; AUMC: area under moment curve; MRT: mean residence time; MAT: mean absorption time; $\mathrm{Vd}_{\mathrm{ss}}$ : volume of distribution at steady state; $\mathrm{Cl}_{\mathrm{tot}}$ : total body clearance; $\mathrm{C}_{\max }$ : maximum plasma concentration; $\mathrm{t}_{\max }$ : time to peak plasma concentration; $\mathrm{F}$ : bioavailability

The elimination half-life in camels $\left(\mathrm{t}_{1 / 2 \beta}\right)$ was $1.95 \mathrm{~h}$. Similar findings were recorded for cefoperazone in dogs (1.40 h; Montesissa et al., 2003), for cefepime in camels ( $2 \mathrm{~h}$; Goudah et al., 2009), longer than cefoperazone in calves $(0.89 \mathrm{~h}$; Carli et al., 1986), horses (0.77 h; Soraci et al., 1996) and shorter than other cephalosporins in camels such as ceftiofur (3.18 h; Goudah, 2007) and ceftazidime (2.85 h; Goudah and Hasabelnaby, 2013).

The $\mathrm{V}_{\mathrm{dss}}$ of cefoperazone was small $(0.38 \mathrm{~L} / \mathrm{kg})$; this value is close to those reported for ceftriaxone in camels $(0.32 \mathrm{~L} / \mathrm{kg}$; Goudah, 2008), higher than data reported for cefoperazone in sheep $(0.16 \mathrm{~L} / \mathrm{kg}$; Guerrini et al., 1985), ceftiofur and cefepime in camels $(0.13 \mathrm{~L} / \mathrm{kg}$ and $0.1 \mathrm{~L} / \mathrm{kg}$, respectively; Goudah, 2007; Goudah et al., 2009), and lower than cefoperazone in horses $(0.68 \mathrm{~L} / \mathrm{kg}$; Soraci et al., 1996) and unweaned calves $(0.71 \mathrm{~L} / \mathrm{kg}$; Soback and Ziv, 1989).

The total body clearance of cefoperazone was $0.17 \mathrm{~L} / \mathrm{h} / \mathrm{kg}$. Similar findings were reported for cefoperazone in sheep $(0.11 \mathrm{~L} / \mathrm{h} / \mathrm{kg}$; Guerrini et al., 1985). In contrast, a higher clearance of cefoperazone was recorded in horses $(0.72 \mathrm{~L} /$ $\mathrm{h} / \mathrm{kg}$; Soraci et al., 1996) and a lower clearance was recorded for ceftiofur and cefepime in camels $(0.03$ and $0.04 \mathrm{~L} / \mathrm{h} / \mathrm{kg}$, respectively; Goudah, 2007; Goudah et al., 2009), and these differences could be correlated to interspecies differences in drug elimination and metabolism.

The higher value of clearance of cefoperazone in camels suggests that there is negligible tubular reabsorption and cefoperazone is primarily excreted 
through glomerular filtration. This finding is in agreement with the results reported in humans (Barbhaiya et al., 1990).

Species differences in pharmacokinetic parameters are relatively common and are frequently related to inter-species variation, the length of period between blood samplings, the assay method used, as well as the age and the health status of the animal (Haddad et al., 1985).

After a single IM administration, cefoperazone was rapidly and efficiently absorbed in camels, as the $\mathrm{t}_{1 / 2 \mathrm{ab}}$ was $0.45 \mathrm{~h}$. This result was reasonably similar to that reported for cefoperazone in dogs $(0.48 \mathrm{~h}$; Montesissa et al., 2003) and longer than that reported for cefoperazone in horses $(0.04 \mathrm{~h}$; Soraci et al., 1996) and for ceftiofur and ceftriaxone in camels $(0.34$ and $0.29 \mathrm{~h}$, respectively; Goudah, $2007,2008)$. The $\mathrm{t}_{1 / 2 \beta}$ of cefoperazone in camels was $2.84 \mathrm{~h}$, which is longer than that reported in calves $(0.79$ h; Carli et al., 1986), horses (1.52 h; Soraci et al., 1996), longer than that reported for ceftriaxone in camels (1.76 h; Goudah, 2008) and shorter than that reported for ceftiofur in camels (3.29 h; Goudah, 2007). The $\mathrm{t}_{1 / 2 \beta}$ after IM administration $(2.84 \mathrm{~h})$ was significantly longer than that obtained after IV administration $(1.95 \mathrm{~h})$. This difference is probably the result of continued absorption of cefoperazone from the IM injection site during the elimination phase, thereby prolonging the $\mathrm{t}_{1 / 2 \beta}$ of cefoperazone.

The $\mathrm{C}_{\max }$ of cefoperazone after IM administration in camels was $21.95 \mu \mathrm{g} /$ $\mathrm{mL}$, very similar to that observed for cefoperazone in $\operatorname{dogs}(24.5 \mu \mathrm{g} / \mathrm{mL}$; Montesissa et al., 2003) and higher than that reported for cefoperazone in calves and horses (7.91 and $7.98 \mu \mathrm{g} / \mathrm{mL}$, respectively; Carli et al., 1986; Soraci et al., 1996), and lower than that reported for ceftazidime in camels $(32.43 \mu \mathrm{g} / \mathrm{mL}$; Goudah and Hasabelnaby, 2013). The absorption process was rapid with a $t_{\max }$ of $1.23 \mathrm{~h}$, which was similar to that of ceftiofur $(1.22 \mathrm{~h})$ and ceftazidime $(1.21 \mathrm{~h})$ in camels (Goudah, 2007; Goudah and Hasabelnaby, 2013). The MRT was longer after IM administration $(4.26 \mathrm{~h})$ than after IV dosing $(2.16 \mathrm{~h})$, as the MRT after IM administration depends on both the disposition and absorption rates.

The IM bioavailability was $89.42 \%$, which is very similar to that of cefepime in camels $(91.7 \%)$, higher than that of cefoperazone in calves $(44.15 \%$; Carli et al., 1986), horses (42\%; Soraci et al., 1996), dogs (41.4\%; Montesissa et al., 2003) and lower than that of ceftiofur in camels (97.4\%; Goudah, 2007).

The pharmacokinetics of many drugs has been found to be different in camels than in other animals. The species differences might be multifactorial and might depend on the metabolic rate of drugs (Ali et al., 1996).

In conclusion, cefoperazone might be a promising alternative treatment for a variety of infectious diseases in camels due to its favourable pharmacokinetic profile. Further studies on tissue distribution and specific determination of the minimum inhibitory concentration (MIC) of cefoperazone for the major bacteria responsible for diseases in camels should be performed in order to obtain more complete efficacy data of cefoperazone in camels. 


\section{References}

Ali, B., Oukessou, M. and Bashir, A. (1996): Pharmacokinetic considerations in the camel (Camelus dromedarius): a review. Comp. Biochem. Physiol. C Pharmacol. Toxicol. Endocrinol. 115, 1-9.

Attia, T., El-Komy, A., El-Hewaity, M., El Latif, A. A. and El-Hanbally, S. (2015): Comparative pharmacokinetics of cefoperazone following intravenous and intramuscular administration in goats. Int. J. Vet. Sci. Med 3, 21-25.

Barbhaiya, R. H., Forgue, S. T., Gleason, C. A., Knupp, C. A., Pittman, K. A., Weidler, H. and Martia, R. R. (1990): Safety, tolerance and pharmacokinetic after multiple intravenous administrations in healthy subjects. Antimicrob. Agents Chemother. 34, 1118-1122.

Carli, S., Montesissa, C., Sonzogni, O. and Madonna, M. (1986): Pharmacokinetic of sodium cefoperazone in calves. Pharmacol. Res. Commun. 18, 481-490.

Gibaldi, M. and Perrier, D. (1982): Noncompartmental analysis based on statistical moment theory. In: Swarbrick, J. (ed.) Pharmacokinetics. 2nd edition. Marcel Dekker Inc., New York. pp. $409-417$.

Goudah, A. (2007): Pharmacokinetics of ceftiofur after single intravenous and intramuscular administration in camels (Camelus dromedarius). J. Vet. Pharmacol. Ther. 30, 371-374.

Goudah, A. (2008): Pharmacokinetic parameters of ceftriaxone after single intravenous and intramuscular administration in camels (Camelus dromedarius). Res. Vet. Sci. 84, 483-489.

Goudah, A. M. and Hasabelnaby, S. M. (2013): Pharmacokinetics and distribution of ceftazidime to milk after intravenous and intramuscular administration to lactating female dromedary camels (Camelus dromedarius). J. Am. Vet. Med. Assoc. 243, 424-429.

Goudah, A., Shin, H. C., Kim, J. S., Chang, B. J., Shim, J. H. and Abd El-Aty, A. (2009): Evaluation of single-dose pharmacokinetics of cefepime in healthy bull camels (Camelus dromedarius). J. Vet. Pharmacol. Ther. 32, 393-396.

Goyal, S., Chaudhary, R. and Srivastava, A. (2005): Pharmacokinetics following intramuscular administration and dosage regimen for cefoperazone in buffalo calves. Indian J. Anim. Sci. 75, 31-32.

Guerrini, V. H., Filippich, L. J., Cao, G. R., English, P. B. and Bourne, D. W. (1985): Pharmacokinetics of cefaronide, ceftriaxone and cefoperazone in sheep. J. Vet. Pharmacol. Ther. 8, 120-127.

Gupta, J. K., Chaudhary, R. K. and Dumka, V. K. (2008): Pharmacokinetics after single intramuscular administration and in vitro plasma protein binding of cefoperazone in cross bred calves. Vet. Arhiv 78, 441-448.

Haddad, N. S., Pedersoli, W. M., Ravis, W. R., Fazeli, M. H. and Carson, R. L. (1985): Combined pharmacokinetics of gentamicin in pony mares after a single intravenous and intramuscular administration. Am. J. Vet. Res. 46, 2004-2007.

Haghgoo, S., Hasegawa, T., Nadai, M., Wang, L., Nabeshima, T. and Kato, N. (1995): Effect of a bacterial lipopolysaccharide on biliary excretion of a beta-lactam antibiotic, cefoperazone, in rats. Antimicrob. Agents Chemother. 39, 2258-2261.

Marino, E. L., Fernandez Lastra, C., Gonzalez Alonso, I. and Dominguez-Gil, A. (1987): Disposition and excretion of cefoperazone in rabbits. Arzneimittelforschung 37, 359-349.

Montesissa, C., Villa, R., Anfossi, P., Zanoni, R. and Carli, S. (2003): Pharmacodynamics and pharmacokinetics of cefoperazone and cefamandole in dogs following single dose intravenous and intramuscular administration. Vet. J. 166, 170-176.

Soback, S. and Ziv, G. (1989): Pharmacokinetics of single doses of cefoperazone given by the intravenous and intramuscular routes to unweaned calves. Res. Vet. Sci. 47, 158-163.

Soraci, A. L., Mestorino, O. N. and Errecalde, J. O. (1996): Pharmacokinetics of cefoperazone in horses. J. Vet. Pharmacol. Ther. 19, 39-43.

Yamaoka, K., Nakagawa, T. and Uno, T. (1978): Statistical moments in pharmacokinetics. J. Pharmacokinet. Biopharm. 6, 547-558. 